\title{
Performance of a Commercial Polymerase Chain Reaction Test for Endocervical Chlamydia trachomatis Infection in a University Hospital Population
}

\author{
C.H. Livengood III,* K.A. Boggess, J.W. Wrenn, and A.P. Murtha \\ Department of Obstetrics and Gynecology and Chlamydia Laboratory, Duke University Medical \\ Center, Durham, $N C$
}

\begin{abstract}
Objectives: To examine the accuracy of a commercial polymerase chain reaction (PCR) test (Amplicor CT ${ }^{\mathrm{R}}$, Roche Diagnostic Systems, Branchburg NJ) for identification of endocervical chlamydial infections through both laboratory evaluation and among a diverse teaching hospital patient population.

Methods: Testing of reliable threshold inocula and reproducibility were carried out using laboratory stock organisms. Paired endocervical samples from patients with a wide range of indications were tested by PCR and an established culture procedure, and discrepant pairs were further analyzed to determine true results.

Results: Laboratory evaluation suggested that one copy of target DNA from a viable organism consistently yielded a positive result, and test reproducibility was very good, with an overall coefficient of variation of $15 \%$. Compared to true results in 1,588 paired clinical samples from 1,489 women with a $10 \%$ prevalence of infection, the PCR test and culture yielded respective sensitivities of $87.4 \%$ and $78.0 \%$, and negative predictive values of $98.6 \%$ and $97.6 \%$. Specificity and positive predictive value for both tests were $100 \%$. Cost per specimen was nearly identical at $\$ 18.84$ and $\$ 18.88$ respectively. Polymerase inhibitors and organisms lacking target DNA were not found in false-negative PCR samples.

Conclusion: This commercial PCR test is accurate, cost-competitive, and much faster than culture for diagnosis of endocervical chlamydia infections in our population of intermediate prevalence of chlamydial infection. Infect. Dis. Obstet. Gynecol. 6:224-229, 1998. @ 1998 Wiley-Liss, Inc.
\end{abstract}

hlamydia trachomatis, serovars $\mathrm{D}-\mathrm{K}$, is widely believed to be the most common sexually transmitted bacterial pathogen in the United States. Reporting of these infections began in 1995, revealing only about 500,000 cases annually, but compliance with reporting (particularly among men) is felt to be quite limited. ${ }^{1}$ Estimates of 3-4 million cases per year are probably more representative. ${ }^{2}$ Further, reproductive morbidity arising from genital chlamydial infection exceeds that of any other cause of infertility, ${ }^{3}$ ectopic pregnancy, ${ }^{4}$ pelvic inflammatory disease, ${ }^{5}$ and neonatal pneumonia, ${ }^{6}$ and it is an important contributor to adverse pregnancy outcome ${ }^{7}$ and failure of assisted reproduction. ${ }^{8}$ Diagnosis of genital chlamydial infection has been problematic. The majority of affected women are asymptomatic and thus do not seek testing. Epidemiologic paradigms to identify those who should be tested have been ineffectual, ${ }^{9}$ with the exception of annual screening of all sexu-

*Correspondence to: Dr. Charles H. Livengood III, Box 3291, Duke Hospital, Durham, NC 27710. 
ally active adolescent and young adult women, which is highly effective. ${ }^{10,11}$ These serovars are poor antigens, so serodiagnosis has not been helpful. Identification of the organism by more affordable tests such as enzyme immunoassay, ${ }^{12}$ direct fluorescent antibody staining, ${ }^{13}$ Pap test, ${ }^{14}$ and DNA probes ${ }^{15}$ is relatively insensitive. Culture of the organism is slow, labor intensive, and expensive but has traditionally been taken as the gold standard for laboratory diagnosis of genital chlamydial infection. Recently, DNA amplification tests have emerged as competitors for the preferred method for diagnosis. Given the value of broadly based screening for prevention of genital chlamydial infection and its complications as recommended by the Centers for Disease Control and Prevention (CDC),${ }^{16}$ extensive information on the performance of various laboratory tests for $G$. trachomatis in geographically and culturally diverse settings is important. We therefore undertook this study to determine the relative accuracy of culture and polymerase chain reaction (PCR)-based testing among our southeastern U.S., hospital-based patient population where chlamydial infections are of intermediate prevalence.

\section{SUBJECTS AND METHODS}

Laboratory evaluation of PCR testing for $C$. trachomatis was undertaken prior to initiation of clinical testing. Using dilutions of low-titer positive control stock employed in our culture system (C. trachomatis serovar $\mathrm{E}$ ), we calculated the threshold number of target DNA copies needed to consistently yield a positive PCR result. Further, we assessed the reproducibility of the test in our hands among different assays by repetitive testing of a sample that gave results in the quantifiable range of the test, absorbance 0 to 3 , in accord with the NCGLS EP5T guideline.

From October 1996 to April 1997, unselected women attending obstetric, gynecologic, and emergency clinics at our institution for whom testing for genital chlamydia was felt by their clinicians to be indicated were candidates for this study. Indications included pelvic pain, cervicitis, presence of other S'TD, risk factors for STD, symptomatic partner, new obstetric patient screening, asymptomatic sexually active adolescents and young adults, and others. No characteristic excluded patients from participation, and samples were excluded from analysis only if they were not endocervical swabbings or if they were rejected for reasons of improper transport or identification. Chlamydia specimens were obtained after all other endocervical samples were taken. The culture specimen was taken first, rotating a Dacron-tipped, plastic stick swab in the endocervical canal and transporting it in $2 \mathrm{M}$ sucrose-phosphate medium at $4^{\circ} \mathrm{C}$ to the laboratory within $24 \mathrm{hr}$. The PCR specimen was then taken using the same technique; the swab was rotated and squeezed out in the manufacturer's transport medium and discarded. The transport medium was held at room temperature or refrigerated before delivery to the laboratory within $24 \mathrm{hr}$ for processing. Verbal consent was obtained from each patient for the additional endocervical swabbing, as approved by our institutional review board. Results of PCR testing were in no case made available outside the laboratory.

The PCR test used, Amplicor CT ${ }^{\circledR}$ (Roche Diagnostic Systems, Branchburg, NJ) was carried out according to the manufacturer's procedure by personnel who had successfully completed the standard three-day training course offered by the manufacturer. Briefly, the test employs biotinylated primers targeting a highly conserved 207 base pair segment in the genome of a cryptic plasmid found exclusively in all serotypes of $C$. trachomatis. In the presence of thermostable polymerase and deoxyribonucleotide triphosphates, thermocycling reproduces each copy of target DNA to (in theory) $10^{9}$ copies after 30 cycles. Copies are then bound, excess reagent washed out, and avidin-peroxidase added. Biotinylated target DNA in the sample binds the avidin, and colorimetric changes induced by peroxidase, measured spectrophotometrically at 450A, signify the presence of target DNA. A nuance of this system is the addition of uracil $\mathrm{N}$ glycosylase, which destroys amplified DNA under ambient conditions, thus minimizing the risk of contamination of other specimens in the laboratory. All specimens were assayed in duplicate. If absorbance results in both aliquots was $\geq 0.5$, the specimen was positive for $C$. trachomatis; if $<0.2$, negative. If either aliquot fell in the range $\geq 0.2$ to $<0.5$, the specimen was assayed again in triplicate and reported as positive if three or more of the five results was $\geq 0.25$, negative if three or more were < 0.25 . Our culture technique has been previously reported. ${ }^{17,18}$ Briefly, shell vials containing a cov- 
erslip with a monolayer of McCoy cells were inoculated in duplicate with clinical specimen by centrifugation at $1,700 \mathrm{~g}$ at $35^{\circ} \mathrm{C}$ for $1 \mathrm{hr}$, then incubated at $35^{\circ} \mathrm{C}$ in 5\% $\mathrm{CO}_{2}$ for 64-68 hours in medium containing cycloheximide to suppress cellular activity. One of the aliquots was then blindly subcultured to another monolayer, which was then treated identically to the primary culture sequence. The other coverslip was stained with iodine and examined at $400 \times$ magnification for cellular inclusions of $C$. trachomatis. A positive result consisted of one or more typical inclusions in the primary or passage culture. Equivocal specimens and those with few inclusions were independently evaluated by two experienced observers, and both must have interpreted it as positive for a final positive result to be assigned. If either observer interpreted a specimen as negative or if no typical inclusions were seen, a negative result was issued.

Discrepancy analysis followed predetermined rules. For all discrepant pairs, culture and the plasmid-target PGR test were repeated. In addition, among the first 600 samples, PCR using primers targeting DNA coding for the major outer membrane protein (MOMP) of $G$. trachomatis was conducted. Results of the plasmid-target and MOMPtarget PCR tests agreed in every case, so MOMPtarget PCR testing was discontinued for the balance of the study. True-positive samples were defined as those that were: 1) culture-positive and PCR-positive on initial testing, 2) culture-positive and PCR-negative on initial testing, and 3) culturenegative and PCR-positive on initial testing and positive by repeat culture or PCR testing. Thus, all samples with a positive culture were taken as truepositive regardless of PCR result. True-negative samples were defined as those that were: 1) culture-negative and PCR-negative on initial testing and 2) culture-negative and PCR-positive on initial testing and negative by repeat culture and PCR testing.

Available PCR specimens from culture-positive, PCR-negative pairs were tested for the presence of polymerase inhibitors by repeat PCR testing of the specimen after "spiking" it with a low-titer positive control standard-a negative result from this mixture indicates the presence of polymerase inhibitors in the specimen. Test cost analysis was undertaken by evaluation of direct expenses over a six-month interval for reagents, supplies, and ma-
TABLE I. Results of reproducibility testing of PCR-based detection of C. trachomatis

\begin{tabular}{lcc}
\hline Sample & $\begin{array}{c}\text { Negative } \\
\text { control }\end{array}$ & $\begin{array}{c}\text { Positive } \\
\text { test sample }\end{array}$ \\
\hline Number of replicates assayed & 80 & 80 \\
Replicates in expected range (\%) & 100 & 100 \\
Mean absorbance & 0.051 & 1.446 \\
Standard deviation & & \\
Within-run & 0.0010 & 0.1212 \\
Between-run & 0.0005 & 0.2667 \\
Between-day & 0.0012 & 0 \\
Total & 0.0016 & 0.2182 \\
Coefficient of variation (\%) & & \\
Within-run & 1.94 & 8.25 \\
Between-run & 1.01 & 18.16 \\
Between-day & 2.40 & 0 \\
Total & 3.19 & 15.09 \\
\hline
\end{tabular}

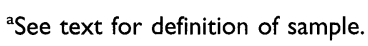

terials used in the performance of each test; amortized cost of equipment based on manufacturer's estimate of life span; and the assumption that one FTE for culture and 0.8 FTE for PCR for a senior technologist were required. Indirect costs such as physical plant, quality control, and administration were not included. The costs were then divided by the number of specimens assayed during the interval. Our laboratory typically processes about 5,000 specimens annually.

The McNemar statistical test was used to compare test results with statistical significance set at $P<0.05$.

\section{RESULTS}

Positive threshold evaluation of the PCR test employed the low-titer control used in our culture system, which over the years has reliably produced a mean of 3.6 inclusion-forming units/100 $\mu \mathrm{L}$ sample. Through trial and error we found that 1:24 was the greatest dilution of this stock which consistently produced a positive result in the PCR test, which employs a $50-\mu \mathrm{L}$ sample. It is known that each viable $G$. trachomatis organism contains about 10 copies of target DNA. Thus, we calculate that approximately one copy of target DNA is needed to consistently yield a positive PCR result $(3.6 \times 10$ $\times 0.5 / 24)$. Reproducibility testing employed that 1:24 dilution of stock positive control, and those results are shown in Table 1.

Results from culture and PCR testing were available from 1,588 paired endocervical samples from 1,489 women. Table 2 shows the demograph- 
TABLE 2. Demographic characteristics of patients providing specimens for evaluation of PCR-based testing for $C$. trachomatis

\begin{tabular}{lc}
\hline Age (mean yrs. \pm SD) & $28.7 \pm 9.3$ \\
Race & \\
Black & $1,009(67.8 \%)$ \\
White & $363(24.4 \%)$ \\
Other/unknown & $117(7.7 \%)$ \\
Marital status & \\
Single & $1,000(67.2 \%)$ \\
Married & $309(20.8 \%)$ \\
Unknown & $180 .(11.9 \%)$ \\
\hline
\end{tabular}

ics of the group. Table 3 shows the correlation of initial culture and PCR testing. Results of discrepancy resolution testing of all culture-negative/PCRpositive pairs is shown in Table 4, along with the retesting done for culture-positive/PCR-negative pairs, which was limited because our protocol predetermined that all culture-positive samples were true-positive. Finally, initial results of each test were compared with true results determined by discrepancy resolution. (Table 5).

None of nine PCR specimens from PCRnegative/culture-positive pairs showed evidence of polymerase inhibitors. Cost per specimen analysis for the two tests showed remarkable similarity in our laboratory. A typical PCR test cost $\$ 9.37$ for materials and $\$ 9.47$ for labor (total, $\$ 18.84$ ). The corresponding figures for culture were $\$ 4.30$ and $\$ 14.58$ (total, $\$ 18.88$ ), respectively.

\section{DISCUSSION}

Our calculation that one copy of target DNA in the specimen will consistently produce a positive result in the Amplicor CT test is in keeping with the mechanisms of PCR technology. However, the calculation assumes the presence of DNA from viable organisms only. The proportion of target DNA in our specimen derived from viable organisms is not known but should be high based on the procedures used to prepare our stock, which exclude cell debris. Because each viable organism in a clinical specimen carries 10 copies of target DNA, we are comfortable that a single organism will yield a positive PCR test under proper conditions. Our reproducibility testing shows excellent consistency of the test and is comparable to results provided by the manufacturer. It should be noted, however, that reproducibiity of this test among a subset of samples with equivocal results has recently been called into question. ${ }^{19}$
TABLE 3. Outcome of initial testing for C. trachomatis by culture and PCR in I,588 paired samples*

\begin{tabular}{lcc}
\hline & \multicolumn{2}{c}{ Culture } \\
\cline { 2 - 3 } PCR & Positive & Negative \\
\hline Positive & 104 & 35 \\
& $(6.5 \%)$ & $(2.2 \%)$ \\
Negative & 20 & 1,429 \\
& $(1.3 \%)$ & $(90.0 \%)$ \\
\hline
\end{tabular}

$* P<0.01$ (McNemar test).

TABLE 4. Results of discrepancy resolution testing in the comparison of culture and PCR-based testing for $C$. trachomatis

\begin{tabular}{lccccc}
\hline & \multicolumn{2}{c}{$\begin{array}{c}\text { Culture-negative/ } \\
\text { PCR-positive }\end{array}$} & & \multicolumn{2}{c}{$\begin{array}{c}\text { Culture-positive/ } \\
\text { PCR-negative }\end{array}$} \\
\cline { 2 - 3 } $\begin{array}{l}\text { Initial test } \\
\text { results }\end{array}$ & Positive & Negative & & Positive & Negative \\
\hline $\begin{array}{l}\text { Repeat culture } \\
\text { Repeat plasmid- } \\
\text { primer PCR }\end{array}$ & $1 / 11$ & $10 / 11$ & & $1 / 8$ & $7 / 8$ \\
$\begin{array}{l}\text { MOMP-primer } \\
\text { PCR }\end{array}$ & $35 / 35$ & $0 / 35$ & & $2 / 8$ & $6 / 8$ \\
\cline { 1 - 2 } & $13 / 13$ & $0 / 13$ & & $2 / 8$ & $6 / 8$ \\
\hline
\end{tabular}

TABLE 5. Performance of culture and PCR-based testing compared to true results determined by discrepancy resolution

\begin{tabular}{lcc}
\hline & $\begin{array}{c}\text { True positive } \\
(\mathrm{n}=159)\end{array}$ & $\begin{array}{c}\text { True negative } \\
(\mathrm{n}=1429)\end{array}$ \\
\hline PCR positive & $139(87.4 \%)$ & 0 \\
PCR negative & $20(12.6 \%)$ & $1429(100 \%)$ \\
Culture positive & $124(78.0 \%)$ & 0 \\
Culture negative & $35(22 \%)$ & $1429(100 \%)$ \\
\hline
\end{tabular}

The population of women we studied is a mixture of high-risk patients and those at lower risk who were subject to screening protocols. This mixture is typical of hospital-based practices. Additional data on patient characteristics were not prospectively collected, as they apparently have little significance with regard to risk for chlamydia genital infection, ${ }^{9}$ and no data suggest that they impact test accuracy. The prevalence of cervical infection by $C$. trachomatis in our population was $10 \%$, intermediate between private office practices and STD clinics. The PCR-based test performed very well in this setting, with results of initial testing in agreement with our established culture technique in $96.5 \%$ of specimen pairs. Further, after identification of true results for each specimen by discrepancy analysis, the PCR test yielded sensitivity of 
$87.4 \%$, specificity of $100 \%$, and negative- and positive-predictive values of $98.6 \%$ and $100 \%$,respectively. The corresponding values for culture were $78.0 \%, 100 \%, 97.6 \%$, and $100 \%$. These values, including the trend toward better sensitivity with PCR than culture, are comparable to those found in other studies that also employed high-quality culture techniques. ${ }^{20-23}$

We feel that our decision to count all culturepositive pairs as true-positive is well founded. This approach was also used by Bauwens et al. ${ }^{24}$ Loeffelholz et al. ${ }^{21}$ found all of 113 culture-positive/ PCR-negative pairs to be true-positive after discrepancy resolution, as did Bass et al. ${ }^{20}$ among all of 74 such samples. Further, we applied very stringent criteria for interpretation of a positive culture result. We use iodine stain which enhances test specificity-probably at the cost of sensitivity ${ }^{25}$ when compared to fluorescent antibody stain, because it provides for evaluation of inclusion morphology. Using criteria recommended by the CDC, ${ }^{18}$ two experienced observers were required to conclude independently that inclusion location, color, granularity, peripheral clearing, and nuclear indentation were all appropriate for a positive result.

Moreover, as discussed by Green et al., ${ }^{26}$ the bias associated with discrepancy analysis-based estimates of PCR test sensitivity is minimized by assigning high specificity to culture results. We were not surprised that reculture of specimens from culture-positive discrepant pairs was often negative, as all of them showed low-titer infectivity initially, and the detrimental effect of an additional freeze-thaw cycle on inclusion count is well known. ${ }^{27}$ We believe the insensitivity of direct fluorescent antibody stain and enzyme immunoassay tests make them inappropriate for use in resolving disagreement between culture and PCRbased tests. Ligase chain reaction testing was not available to us at the time of this study.

Inhibitors of the PCR process have been described in cervical specimens at a frequency of $19 \%$ by Verkooyen et al., ${ }^{28}$ using the method of detection we used. Using more sophisticated methods, Bass et al. ${ }^{20}$ found inhibitors in $4 \%$ of their specimens. We found no evidence of PCR inhibitors in the nine culture-positive/PCR-negative samples we tested. $C$. trachomatis lacking the cryptic plasmid which contains the DNA targeted by Amplicor
CT has been described. ${ }^{29}$ All eight culturepositive/plasmid PCR-negative samples we tested were also negative by PCR testing with primers for MOMP DNA, indicating that chlamydia lacking plasmids was not the explanation for false-negative PCR results in these specimens. Our culturepositive/PCR-negative specimens may have resulted from improper specimen procurement, transport, or processing. We did not monitor the adherence of clinicians to the specimen procurement procedure. Specimen adequacy has been shown to be an important determinant of the sensitivity of this test. ${ }^{30} \mathrm{We}$ were unable to assess this factor because of cytolytic agents included in the transport medium.

Our study suggests that the Amplicor CT PCRbased test for endocervical $C$. trachomatis infection offers accuracy at least equivalent to culture at the same cost, and provides results much more rapidly, in a large population with intermediate prevalence of infection. Where resources provide for it, this PCR test may be the preferred method for laboratory diagnosis of endocervical chlamydial infections.

\section{REFERENCES}

1. Centers for Disease Control and Prevention: Summary of notifiable diseases, United States, 1996. Morb Mortal Wkly Rep 45:1-87, 1997.

2. Centers for Disease Control: Chlamydia trachomatis infections. Policy guidelines for prevention and control. Morb Mortal Wkly Rep 34(Suppl 3):53S-74S, 1985.

3. Moore DE, Foy HM, Daling JR, et al.: Increased frequency of serum antibodies to Chlamydia trachomatis in infertility due to distal tubal disease. Lancet II(8298): 574-577, 1982.

4. Chow JM, Yonekura ML, Richwald GA, et al.: The association between Chlamydia trachomatis and ectopic pregnancy. JAMA 263:3164-3167, 1990.

5. Mardh PA, Ripa T, Svensson L, et al.: Chlamydia trachomatis infection in patients with acute salpingitis. $\mathrm{N}$ Engl J Med 296:1377-1379, 1977.

6. Brasfield DM, Stagno S, Whitley RJ, et al.: Infant pneumonitis associated with cytomegalovirus, chlamydia, pneumocystis, and ureaplasma: follow-up. Pediatrics 79: 76-83, 1987.

7. Gravett MG, Nelson HP, De Rouen T, et al.: Independent associations of bacterial vaginosis and Chlamydia trachomatis infection with adverse pregnancy outcome. JAMA 256:1899-1903.

8. Witkin SS, Kligman I, Grifo JA, et al.: Chlamydia trachomatis detected by polymerase chain reaction corre- 
lates with adverse in vitro fertilization outcome. J Infect Dis 171:1657-1659, 1995.

9. Mosure DJ, Berman S, Fine D, et al.: Genital chlamydia infections in sexually active female adolescents: Do we really need to screen everyone? J Adolesc Health 20:613, 1997.

10. Centers for Disease Control and Prevention: Chlamydia trachomatis genital infections-United States 1995. MMWR Morb Mortal Wkly Rep 46:193-198, 1997.

11. Scholes D, Stergachis A, Heidrich FE, et al.: Prevention of pelvic inflammatory disease by screening for cervical chlamydia infection. N Engl J Med 334:1362-1366, 1996.

12. Taylor-Robinson D, Thomas BJ, Osborn MF: Evaluation of enzyme immunoassay (Chlamydiazyme) for detecting Chlamydia trachomatis in genital tract specimens. J Clin Pathol 40:194-199, 1987.

13. Shafer MA, Vaughan E, Lipkin ES: Evaluation of fluorescein-conjugated monoclonal antibody test to detect Chlamydia trachomatis endocervical infections in adolescent girls. J Pediatr 108:779-783, 1986.

14. Bernal JN, Martinez MA, Dabancens A: Evaluation of proposed cytomorphologic criteria for the diagnosis of Chlamydia trachomatis in Papanicolaou smears. Acta Cytol 33:309-313, 1989.

15. Peterson EM, Oda R, Alexander R, et al.: Molecular techniques for the detection of Chlamydia trachomatis. J Clin Microbiol 27:2359-2363, 1989.

16. Centers for Disease Control and Prevention: 1998 Guidelines for treatment of sexually transmitted diseases. Morb Mortal Wkly Rep 47(No. RR-1):53-59, 1998.

17. Livengood CH III, Schmitt JW, Addison WA, et al.: Direct fluorescent antibody testing for endocervical Chlamydia trachomatis: Factors affecting accuracy. Obstet Gynecol 72:803-809, 1988.

18. Bird BR, Forrester FT: Laboratory Diagnosis of Chlamydia trachomatis Infections. Atlanta: Centers for Disease Control, Bureau of Laboratories, Virology Training Branch, pp 39-79, 1980.

19. Peterson EM, Darrow V, Blanding J, et al.: Reproducibility problems with the Amplicor PCR Chlamydia trachomatis test. J Clin Microbiol 35:957-959, 1997.

20. Bass CA, Jungkind DL, Silverman NS, et al.: Clinical evaluation of a new polymerase chain reaction assay for detection of Chlamydia trachomatis in endocervical specimens. J Clin Microbiol 31:2648-2653, 1993.

21. Loeffelholz MJ, Lewinski CA, Silver SR, et al.: Detection of Chlamydia trachomatis in endocervical specimens by polymerase chain reaction. J Clin Microbiol 30:28472851, 1992.

22. Kay ID, Palladino S, Alexander R, et al.: Evaluation of a commercial polymerase chain reaction assay for the detection of Chlamydia trachomatis. Diagn Microbiol Infect Dis 28:75-79, 1997.

23. Fong CK, Falcone J, Landry ML: Use of a single swab in multi-microbe or flex transport medium for detection of Chlamydia trachomatis by Roche Amplicor PCR and culture. J Clin Microbiol 35:2427-2429, 1997.

24. Bauwens JE, Clark AM, Stamm WE: Diagnosis of Chlamydia trachomatis endocervical infections by a commercial polymerase chain reaction assay. J Clin Microbiol 31:3023-3027, 1993.

25. Stamm WE, Tam M, Koester M, et al.: Detection of Chlamydia trachomatis inclusions in McCoy cell cultures with fluorescein-conjugated monoclonal antibodies. J Clin Microbiol 17:666-668, 1983.

26. Green TA, Black CM, Johnson RE: Evaluation of bias in diagnostic-test sensitivity and specificity estimates computed by discrepant analysis. J Clin Microbiol 36: 375-381, 1998.

27. Aarnaes SL, Peterson EM, DeLa Maza LM: The effect of media and temperature on the storage of Chlamydia trachomatis. Am J Clin Pathol 81:237-239, 1984.

28. Verkooyen RP, Luijendijk A, Huisman WM, et al.: Detection of PCR inhibitors in cervical specimens by using the Amplicor Chlamydia trachomatis assay. J Clin Microbiol 34: 3072-3074, 1996.

29. An Q, Olive DM: Molecular cloning and nucleic acid sequencing of Chlamydia trachomatis $16 \mathrm{~S}$ rRNA genes from patient samples lacking the cryptic plasmid. Mol Cell Probes 8:429-435, 1994.

30. Welsh LE, Quinn TC, Gaydos CA: Influence of endocervical specimen adequacy on PCR and direct fluorescent antibody staining for detection of Chlamydia trachomatis infections. J Clin Microbiol 35:3078-3081, 1997. 


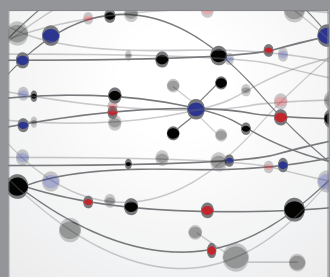

The Scientific World Journal
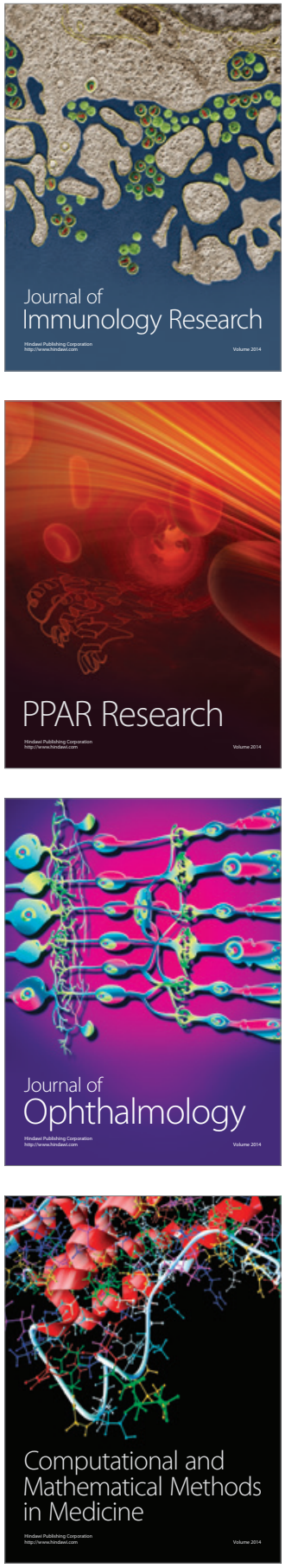

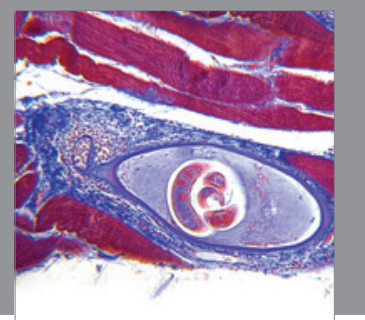

Gastroenterology

Research and Practice
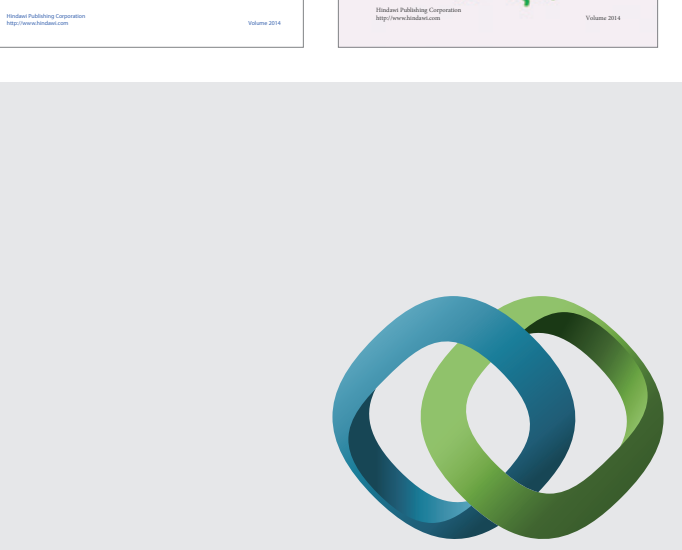

\section{Hindawi}

Submit your manuscripts at

http://www.hindawi.com
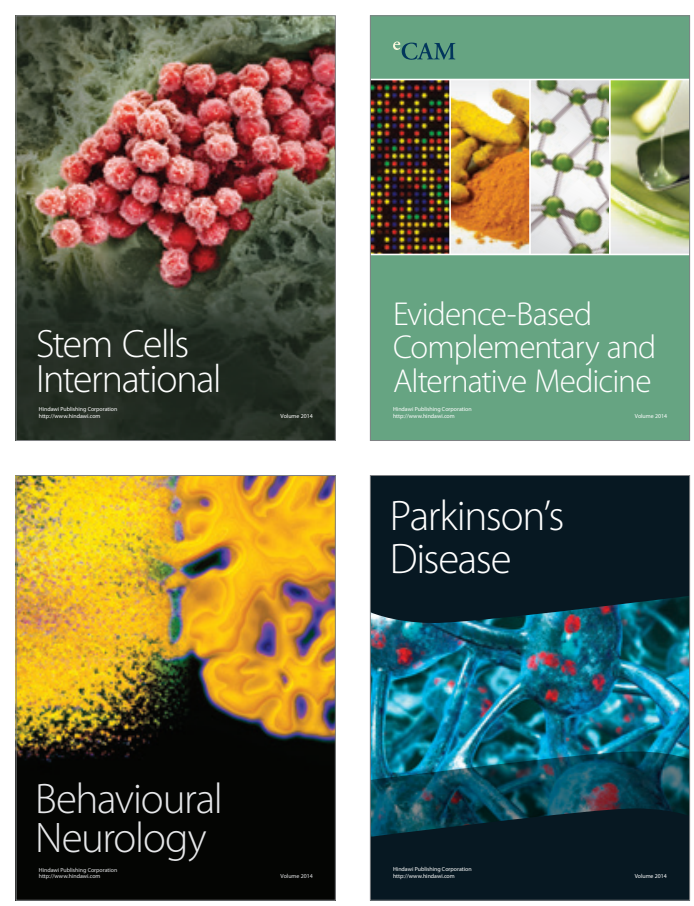

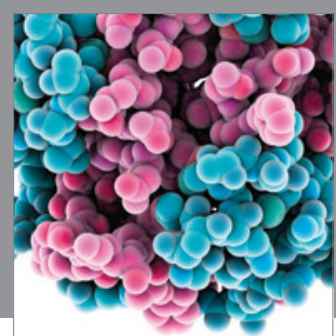

Journal of
Diabetes Research

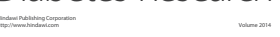

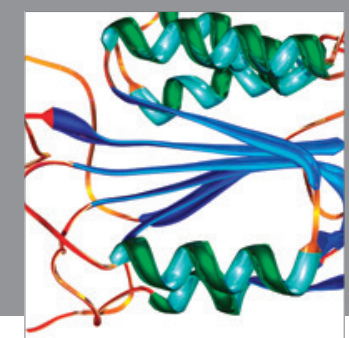

Disease Markers
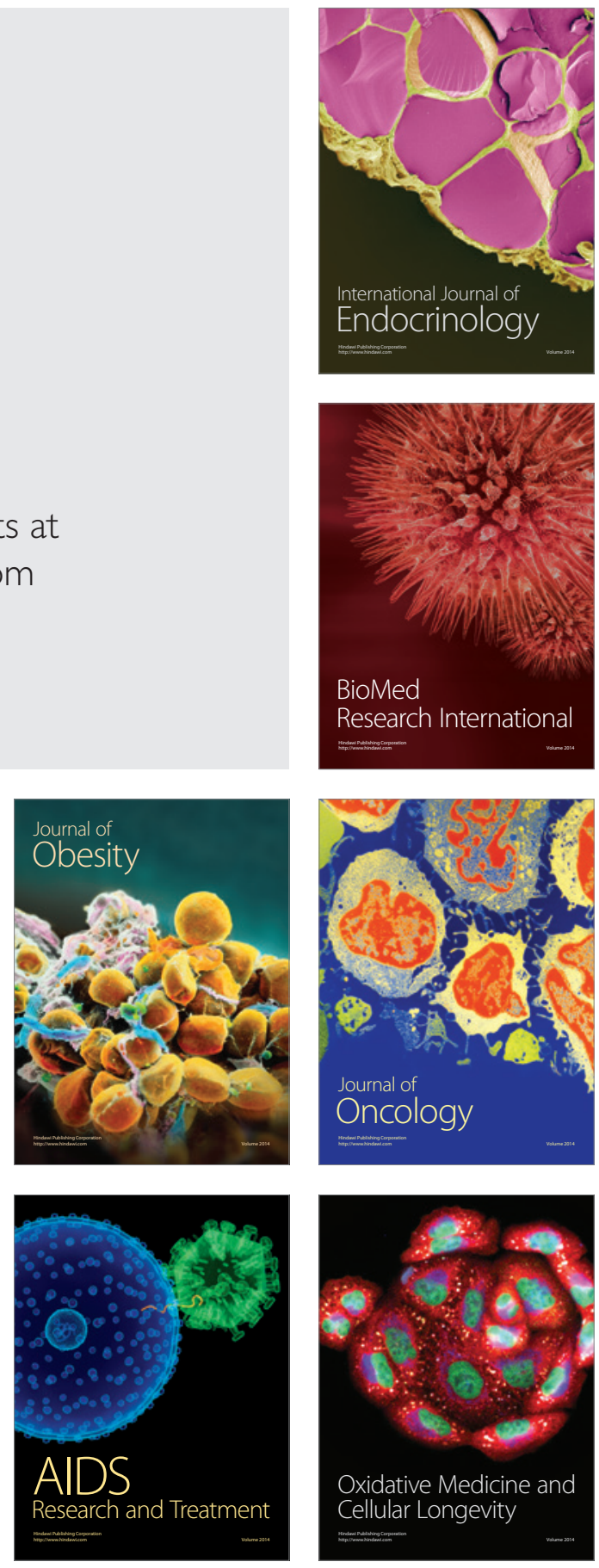